\title{
White Wine Packaging in Traditional Graphics Research
}

\author{
Pingping Yang \\ Yantai Nanshan University \\ Yantai China \\ e-mail:603483773@qq.com
}

\begin{abstract}
The pattern which contains Chinese traditional culture is an important design element of our morden packaging design. Its exploration and research on the liquor packaging design is also a vital way to carry forward the traditional culture and improve the connotation of liquor culture, But it is a continuous process of exploration for the mining and management of traditional culture and to apply it to the liquor packaging design. First of all, the designer itself should have a rich traditional culture connotation, and adopt modern design methods and advanced means to apply it to the liquor packaging. Liquor packaging on the market at present, however, for the design and application of traditional culture are not so good. Under the background of internationalization, tradition is unique, traditional graphics can reflect the cultural connotation and aesthetic thought which has huger significance. Of course, the application of traditional graphics and design also is not invariable. Under the background of the internationalization, it's essential to absorb the essence and discard the dross, and base on the domestic and national markets with a new look.
\end{abstract}

Keywords-liquor packaging design; Traditional graphics; Traditional culture; Aesthetic; innovation

\section{The PATtern of Traditional Chinese Culture}

Traditional graphics from the more general sense, reflect the traditional culture of a certain area, and reflect the typical graphic patterns of different ethnic characteristics in different regions. These graphics have distinctive national features, regional characteristics, and general characteristics, etc. Wine packaging graphics is the dimentation in a long time. Some traditional graphics with aesthetic standard are preserved, and some traditional graphics be forgotten in the long river of history, but the graphics which is inherited is not immutable. As the graphics change over time, packaging graphics design is also a process to select the essence based on the basis of inheritance. We discussed the research of liquor packaging design graphics is a deconstruction and innovation of traditional graphics on the basis of understanding. In circulation through the market, and degree of consumer choice and recognition, to find the best integrating point between traditional and modern, which reflects the background and connotation given traditional things by the time, and perfectly reflects the modern wine packaging design characteristics of traditional graphics.

\section{RESEARCH PURPOSE AND SIGNIFICANCE}

Wine packaging design in the traditional sense is the application of some traditional basic graphics to wine packaging design, some do a bit of simple changes, and some change colors. The traditional pattern studied in this paper discussed the value and significance of contemporary wine packaging design, not just a simple change in the traditional sense. Wine packaging design were discussed from the real sense, both has the cultural connotation and national characteristics, not only conforms to the modern aesthetic idea and show the traditional cultural spirit.

\section{PROJECT BACKGROUND}

Traditional culture with Chinese characteristics is the result of a long development, and the traditional graphics which has a profound meaning laid a solid foundation for the aesthetic development of various dynasties. In Chinese dynasties, art will have to use these graphics or it is a way of derived using. However, in the field of modern wine packaging design, some graphics used lack of systematicness, emphasize on the requirement of liquor manufacturers on the sales, imitate the graphic elements which the wine sells well. Some wine pursues high-end quality blindly, that is to say, a good impression of high-grade wine to the consumers implanted directly into the low-end liquor packaging. Copying, imitating the design is not unusual, so it is difficult to establish a distinctive liquor brand image, not to mention the transmission of the enterprise culture with the characteristic of self let alone convey the enterprise culture. Therefore, in order to avoid the design element and combination of graphic design elements to be monotonous, the bad phenomena of copying, and the deficient graphic creativity. Designer must have a comprehensive knowledge, and other rich professional knowledge, such as history, humanities, geography, customs, consumption and marketing.

Under the background of internationalization, liquor packaging on the brand image is more and more concerned, especially we have the rich local culture. If these traditional cultures are understood, digested, and innovated by wine packaging designers, then our liquor packaging will have the change of the nature, and this design of the modern wine packaging should be promoted. 


\section{THE CLASSIFICATION OF THE TRADITIONAL GRAPHICS IN LIQUOR PACKAGING}

\section{A. The typical grain of bronze art}

The animal graphics

1) the gluttonous grain. Greedy animals are gluttonous, gluttonous animals are gourmands, and gluttony is a kind of animals that represent the greed .They can eat everything, whether plants or animals, the more they become bigger, the more they eat more. So is a kind of animals on behalf of the greedy.

Gluttonous facial structure is clear, formed by several parts, the supercilium, mesh pattern, pattern nose, mouth pattern, ear rings, angular lines. It is shaped like a Wolf, extremely like eating. The animal heads carved on the Ding is its image. Gluttonous graphics are not particularistic enough for modern people, and also more difficult to understand, the face part of the left and right sides is symmetrical, and the texture is more. In early Shang dynasty bronzes, it has been proved that the mature gluttonous graphics can be seen, most of the graphics are in a prominent position in vessels, modeling is relatively large, carved with Yin line. The surface looks smooth, ups and downs. Comparing the early gluttonous graphics, early gluttonous graphics without Yun Lei background, but there are Yun Lei background graphics at late stage "Fig. 1" "Fig. 2".

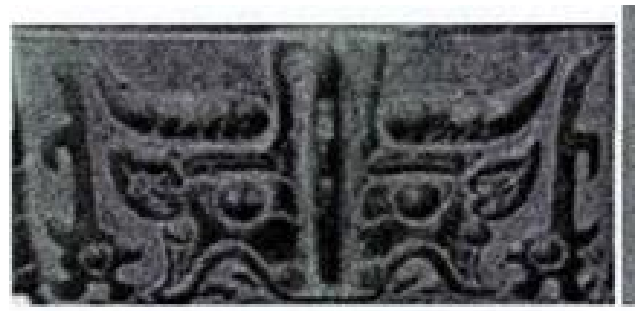

Fig. 1. Early stage

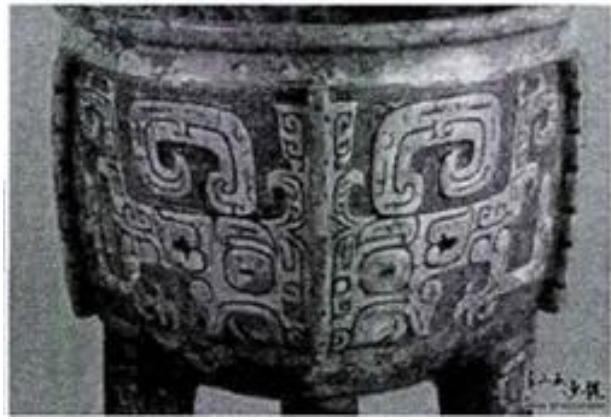

Fig. 2. Late stage

2) the graphics of the dragon. There are many kinds of Dragon pattern, one of them is called change lines. Recorded in Ancient book "change", referring to the animals that have one horn and one feet. In fact, it is a bipedal animal's profile. The beast is shaped like a dragon in myth. The animal face of bronzy ware which decorates many graphics is used frequently until today and the pattern is often the way that embroiders it on tiger-head shoes "Fig. 3".

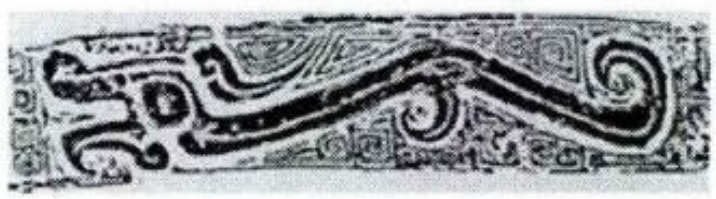

Fig. 3. Crawling dragon

Coil dragon is one of the graphic decoration on the bronze. This graphics belong to suitable patterns "Fig. 4", and the dragon of the whole body form a circle. The central part is the dragon head which has delicate and square graphics. The body parts of the dragon that similar to the snake's body parts will generally simplified, so this way of graphic design is rich and simplified. The graphics are used to pack the parts that tend to be a circular in liquor packaging, and they look satisfactory and harmonious as a whole. The graphics mean good luck, which is also a selling point for businesses to sell it.

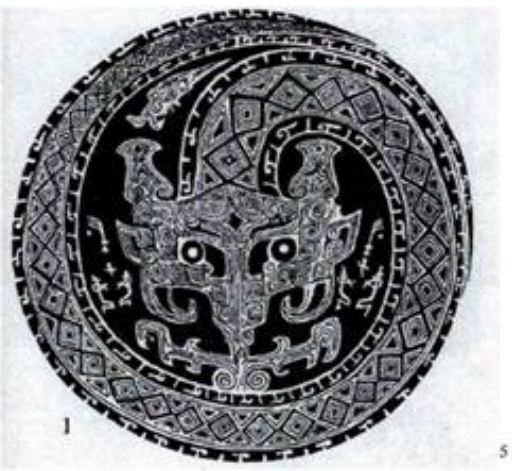

Fig. 4. Coil dragon

Cross dragon is one of the decorative patterns one the bronze "Fig. 5". It includes two or more dragons whose bodies are intertwining. There are many different structures, such as the monomer connection type. Dragon bodies tend to the same direction with an intertwining connection state regularly. There are also many dragon bodies twisted together in fold forms. It is popular in the early spring and the late Warring States .Close and not random. At the same time, the density is natural and the essence of the difficulty in modern pattern is also rare. Most of the graphics used in liquor packaging for background.

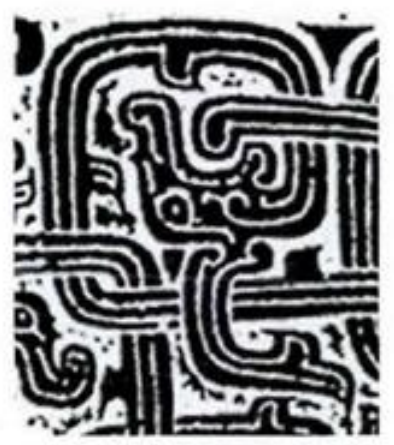

Fig. 5. Cross dragon 


\section{3) the phoenix bird patterns}

Phoenix bird patterns are also one of the ancient Chinese bronze ornamentation. Phoenix, in the ancient legend, as the leader of certainly birds, is the most beautiful flyer among the feather worm, when it flies out of the sky, many birds follow with it. It is regard as the king of birds. In the minds of the ancients, phoenix is a lucky bird. According to the composition of a picture image, the phoenix patterns was divided into long beak bird patterns, owl patterns and geese patterns, then the former's body is a bird and the head has a long beak; the latter with big round eyes and hair angle wing is positive. At the same time, it is popular in the late Shang Dynasty. Goose pattern, is a realistic image of bird patterns in the late spring and Autumn Period, belonging to the northern style.

There is a clear pattern of Bird Figure unearthed jade Liangzhu culture. The earliest used as decoration on the broneze is the two period: Firstly, it is used as decoration on the bronze ware is deformed upper Bird Erligang period; Secondly, it is used as decoration on the bronze ware in the Yin Ruins. In the early western Zhou dynasty, there are a lot of bird patterns graphics, which have been used to the spring and autumn period.

Shang dynasty adopted short-tail bird patterns graphics mostly, while bird patterns of western Zhou dynasty graphics are mostly high long tail comb. There are many Types of graphics, including Bird phoenix, owl pattern, phoenix pattern and the goose lines arranged in groups, etc. Bronze in the Shang and Zhou dynasties, bronze relief or half relieves, which is the main decorative phoenix pattern graphics.

Fenice graphics is one of the bird patterns graphics, and its initial image is similar to the swallows "Fig. 6". Later with the continuous development and integration of tribe and fusion, fenice gradually evolved into a phoenix with a crest, crane foot, and the peacock's tail. In order to show reverence to ancestors, the ancient people used the graphics widely. Fenice is the ancient symbol of the sun bird. Making the sun hanging in the sky connections to the flying birds, which are the good imaginations of ancients. Now the liquor packaging design often quoted phoenix graphics for design, which is also a way to express the people's yearning for a better life.

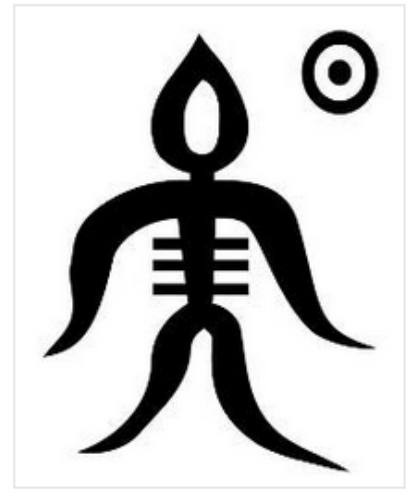

Fig. 6. Fenice graphics
Bronze phoenix design graphics are mostly on face image, and the head and body part is relatively simple, focusing on the performance of the crown and the tail. The two parts are more varied. Coronet, roughly divided into three types: multi-crown phoenix graphics, crown length, corolla grain. It is formed by symmetrical graphics.

The figure is left through many applications "Fig. 7", exaggeration, change and refining legacy of working people's life in usual. Phoenix grain mostly decorated in different vessels of the neck, mouth, stomach, feet, etc. The graphics in the liquor packaging can be used as auxiliary graph. The spirit of the movement is the best in all animals for birds. Bird graphics adorned in liquor packaging reduce the feeling of deterrence, and increase the spice of life.

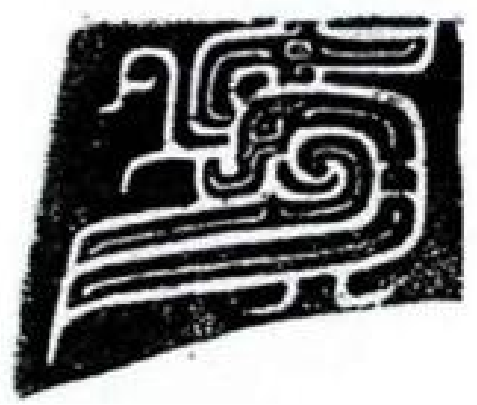

Fig. 7. Phoenix bird patterns

\section{5) as the grain graphics}

The graphics is found in bronze, jade, ceramics. Shang Dynasty, the central plains area of china still has wild elephants. Oracle, there are records of Ying Wang elephant hunting. Design features, proboscis, ivory is obvious, and the body decorated spiral lines. It is filled with Yun Lei lines all around. It is also used as the main grains "Fig. 8". People usually applied it in Fang Yi department, prevailing in the Shang and the early Western Zhou Dynasties.

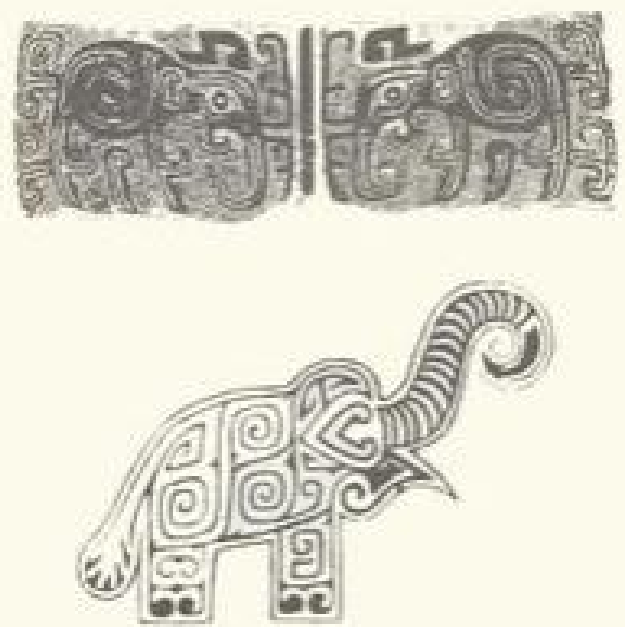

Fig. 8. As the grain graphics 


\section{6) cicada grain graphics}

Cicada pattern is used for bronzes, jades, ceramics, frequently, playing a decorative role .Some of the cicada pattern without feet, like a chrysalis, may be the restoration. So, cicada grain has a symbol of death and rebirth. The graphics prevail in late period of Shang and early period of Zhou.

7) pot shaped strips graphics. The pot body strips are mostly used in the early Western Zhou Dynasty, and the graphical features that are not seen in the previous generation are very strange. However, they are gone in the middle of the Western Zhou Dynasty. The graphic patterns' head is similar to the shape of a dragon, long volume nose, the top of the head has tentacles, and the body parts are similar to the spiral shape. At the same time, there are a claw out under the animal head part. This is the fancy graphics and left behind a deep impression. The pot body strips which is shaped based on a fairy tale's fantasy animal model. The animal doesn't exist in our real life.

\section{The geometric graphics}

Geometric graphics is the earliest decoration appeared on the bronze. In Xia period, there is simple geometric decoration on bronze. In early Shang Dynasty, especially in the valley period, the geometry decorative use have a qualitative leap. Gap between Geometry lines and modern decorative graphic is not big. Geometry graphics are refined from specific decorative graphics from life. It seems difficult to understand. In fact, geometric graphics themselves have their own representatives, and have the typical meaning.

\section{1) alignment lines graphics.}

Alignment graphics is also called Lianzhu lines, alignment, ring of grain, a kind of geometric features of traditional culture is passed down in the history of china ornamentation. It is composed of various connected circulars, and alignment lines graphics' pattern is circulars mostly, just represent the sun. Annular stands for the sun radiation, flake, block, irregular area are very few, and it represents "fire" mostly, namely artificial sun. Artificial sun is the ancients imagination, and is the understanding of the universe relationship after driving out the darkness as messenger. It is a continuation of the prehistoric culture worship of the sun. Due to this meaning, the liquor packaging on the market at present, alignment lines pattern is used and designed constantly.

2)cloud thunder pattern. The graphics earliest appeared in the late period of the new period of pottery "Fig. 9", and the formation of the graphics is mainly according to the basic form of spiral disaster water flow simulation. Generally, we called the spun round graphics the moire, roll moire or volume, and named the square and roundabout posed knuckle graphics as cloud thunder pattern "Fig. 10". The distinguish between the two is not very strict, in the later, the use of the two graphics are often mixed. This is the cloud thunder pattern which we now speak. In the warring states period, the extent of the cloud pattern's change is relatively large. The cloud graphics left the arc-shaped plump shape, and also broke the neat structure as shading. The graphics' lines as a background in the design of the people become more and more smooth, stretch. Its' aesthetic feeling becomes more and more strong. Changes of cloud pattern explains the ancient working people eager to a lively, free way of life "Fig. 11".

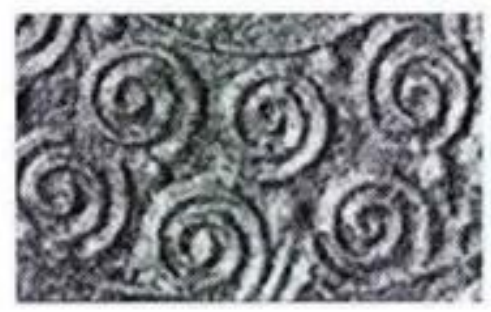

Fig. 9. Cloud pattern

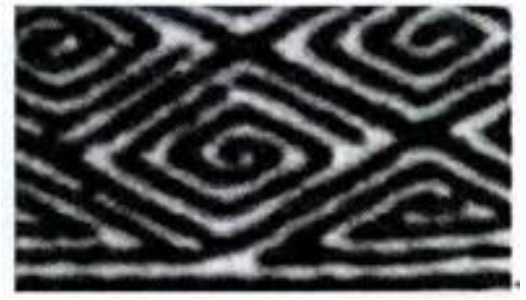

Fig. 10. Thunder pattern

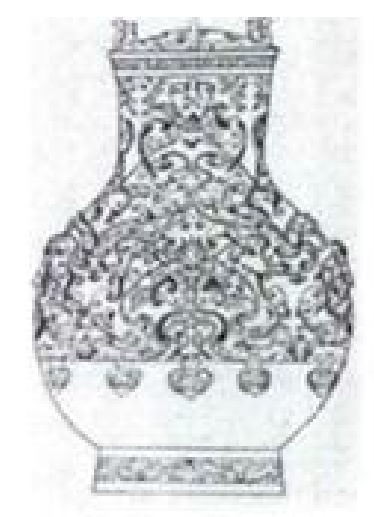

Fig. 11. Cloud pattern during the warring states period

3) steal grain pattern. Stealing graphics is made up of both ends back to hook or "S" shaped lines oblong shape design "Fig. 12", and is often filled with a mesh shape in the middle. The earliest is used in the Western Zhou period, prevailing in the spring and autumn period and the warring states period. Rings with undulating twists, so called "ripple". Some of the ancients also called this graphic "mountain moire or" plate of moire", mainly because of the modelling of the graphics like a mountain in the clouds ups and downs. It mainly used in copper kettles, the abdomen, as the main decorative graphics and is also useful in the bottom of the artifacts. 


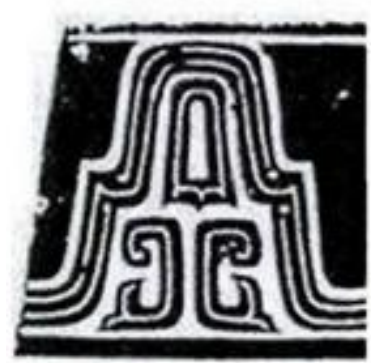

Fig. 12. Steal grain

\section{4) the fire grain and the four disc pattern graphics.}

Fire lines is often known as the representative graphics of the sun, so it's main graphic feature is circular. The ancients thought the sun is fire. Round grain like the sun is called fire lines "Fig. 13". The ancients regard it as a great power of nature to worship. The fire lines on the bronze graphics, portrayed in the round slightly convex surface, and there are three to eight rotary-shaped arc, which was used to represent the flow of flame. Sometimes there is a circle in the center, and sometimes there are not. Or there is no rotating arc. Because the graphics are similar to the shape of the water snails, we also call it the "circular vortex lines", "vortex lines". Usually it is used in GUI jie, tripod, jazz, jia, pots and water container. Fire grain graphics have a single application, also has together with other graphics application for decoration. The graphics are mainly popular in Shang and Western Zhou dynasty.

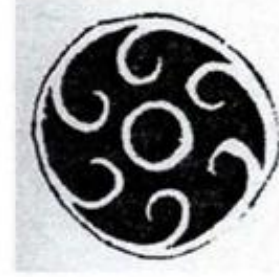

Fig. 13. The fire lines

Four disc pattern is also called the "four disc mu wen". Around the center is square, it is composed of four petals. Some around with thunder pattern. Generally, it forms two straight pattern, as edge decoration. It is found in shang dynasty, during the warring states period, and there are still popular, but its shapes change slightly.

5) heavy circle pattern. Heavy ring likes chains, a ring by ring, and there are a ring, or there are multiple ring. Heavy ring in the western Zhou dynasty more prevalent. Oval ring seems to lock the working people who are eager for free life.

6) vertical scale pattern. Ticking the approximate scale lines and painting the thick lines with main lines and lining with bold lines of thunder pattern. It is used to the lid and bottom, often for edging application. Going through in the late Western Zhou Dynasty and Spring and Autumn period. In addition, there are secretly grain, honnails, string lines and other geometric patterns.

\section{The portrait graphics research.}

Painting lines from the ancient development until now, is more and more smooth. Its modeling is more and more beautiful, and performance is more and more diverse. These graphics content are scenes mostly from the life, showing the ancient upper noble life scenes which are comfortable and enjoyable on life. Life is full of fun. Another picture shows war situation. The ancient war forays, protecting our home from being destroying, also is one of drawing material. For composition of picture, there are a plenty of single scene, and some shows relatively large scene, some combined several scenes.

Mining Sang Yan hunt warriors grain plates "Fig. 14", the plates a tiny mouth, inclined shoulder, drum abdomen, ring foot, shoulder royal two beast ear ring; Pot body full is acted the role of fault pattern, inlaid with triangle moire lines, points, middle and lower three layers: the upper for mulberry hunt figure, middle feast for dimethoate figure, the lower to the battle of the amphibious attack graph. It is delicated, embedded with technology superb, rich in content, and have rigorous structure.

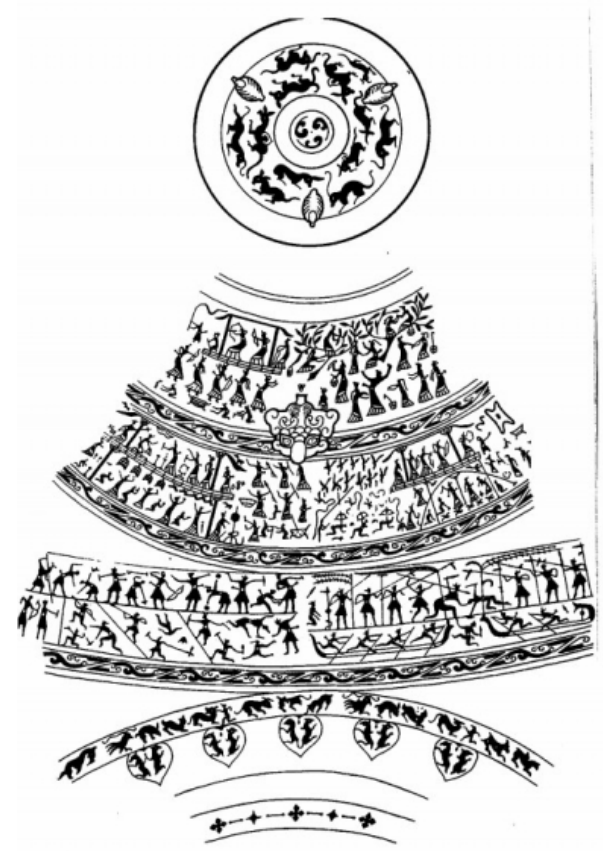

Fig. 14. Mining SangYan hunt warriors grain plates

\section{B. Pottery pattern graphics}

Pottery pattern shape, is painted earthen instruments to a decorative graphic patterns. The patterns of the graphics production process is complicated. Firstly, we should use the method of coloured drawing or pattern on the pottery painting pottery embryo, and then it will be fired .After high temperature firing, charted pattern is printed in the pottery for a long time. Graphics and colour is not only waterproof, also not fall off because of water soaking. Painted pottery are divided into different types because of different areas. There 
are the banpo type and the bottom of the temple groove type, and these two kinds of painted pottery decoration pattern graphics are not the same. The banpo type for animal print graphics, temple bottom groove type, on the basis of the former is more the plants patterns, and then developed into the second consecutive graphics that we often use today

\section{Fangsheng grain graphics}

Fangsheng graphics is a kind of jewelry connected by two rhombus overlapping parts. Later, after the application of the pattern, this kind of jewelry named. As fangsheng grain. Fangsheng grain also is a kind of sweet design, the significance of superior, or piled up because its are two same graphics in the form of a concentric implication, then to yanbian duplication and overlay, also known as Chinese knot.

\section{Is eaves graphics}

Eaves tiles, initially in the Chinese ancient buildings on the roof of a kind of special decorations is a combination of form and the use of an item. His pattern includes the grain of nature, animal grain. Most well known is the "animal lines of the four gods, which represents the southeast northwest of blue dragon, white tiger, rosefinch, xuanwu four god beast image.

Above all, give liquor with auspicious significance of propitious culture in packaging graphics, the auspicious culture representative meaning, whether it be a dragon and phoenix design, the mythical wild animal or flat peach, there are deep blessing. Whether it is copper, tai chi, vases, etc., all have the blessing and the meaning of happy to ward off bad luck. Chinese traditional graphics in the search for and adapt to the new carrier, liquor packaging is the one of the most widely used and the performance of the carrier. Emphasize the nationalization of traditional transmission today, applying traditional graphic and communication development works as design concept, the rich content of Chinese traditional culture, variety, this paper only for containing a small part of the paper, and applied in practice. Another is derived from the actual life, such as grain, ding wen, bricks and other things related to white wine or liquor brand wine figure, shipping figure, such as landscape figure associated with white wine scene, as well as the ink figure, the shepherd boy, image spokesperson associated with white wine, such as the most important thing is that these patterns are not only on the surface of the relevant, and have deeper implied meaning. Either praise liquor has a long history and was Fan-hua Zeng, years of old brand is a inheritance; Either in person feeling, the person's mental or emotional gives the wine of the same quality, reminiscent of the spirit behind the culture, promoting its liquor brand. From graphic patterns on the nationality of the liquor packaging can be found that the thought of "human to ward off bad luck" in the art performance more incisively and vividly, despite differences in cultural habits around, but the common idea is consistent for the Chinese nation. In stores today, it is not hard to find, the people's choice of goods, most based on packing style of love, if a product on the practicality and package have reached satisfaction in people's mind, then surely he is will lead the market trend.

\section{REFERENCES}

[1] Wu Lao, phoenix, design research, zhejiang people's fine arts publishing house, 1984 Hangzhou

[2] "hat, kan, Chinese traditional graphic and modern visual design, shandong pictorial publishing house, 2005 Taiwan

[3] art symbol aesthetics, Beijing broadcasting institute press, 2002

[4] Tang Gulu

[5] the folk art of the cultural ecology theory, tsinghua university press, 2006

[6] shou-zhi wang, the world history of modern design, the China youth press, 2002

[7] guang-lin tian, introduction to Chinese traditional culture, higher education press, 1999

[8] Zhang Daoyi, easy to save, Chinese symbol culture: fugue, huacheng publishing house, 2009

[9] bill yeung, plane and color composition of Chinese painting, xileng printing society press, 2005 